\title{
PERANI, COMPANHEIRO E MESTRE DO CAMINHO*
}

Há pessoas - e não são muitas - que marcam decisivamente a vida da gente. Pe. Cláudio Perani é uma dessas pessoas na minha caminhada.

Em 1981, vindo de São Paulo, interrompendo na metade o curso de Teologia e a perspectiva em crise de ser padre redentorista, cheguei à Bahia da Diocese de Juazeiro, das grilagens de terra, da barragem de Sobradinho e dos projetos de irrigação, do bispo-profeta Dom José Rodrigues, de um reduzido mas afinado grupo de agentes de pastoral e da CPT atuante. Um caminho novo e desafiador se abria e precisava de apoio seguro para trilhá-lo. Logo soube do jesuíta italiano Perani, como o chamávamos, referência para o tipo de pastoral popular que desenvolvíamos ali. Era conhecido também pelas suas posições críticas à Ditadura Civil-Militar (1964-1985) e ao "carlismo"1 na Bahia, e pela guarida que deu a perseguidos pelo regime.

Os Cadernos do CEAS, publicação do Centro de Estudos e Ação Social, dos jesuítas em Salvador, que ele dirigia, forneciam luz e força naqueles tempos bicudos e cheios de esperança na resistência popular, como ele mesmo nos fez enxergar. Sob a censura, não haviam sobrevivido outras publicações nesta linha. Sem os Cadernos, estaríamos provavelmente, ainda mais perdidos. Semente bem plantada, árvore generosa, mais de 50 anos depois os Cadernos continuam.

Soube que, pelo CEAS, Perani havia procurado o bispo anterior de Juazeiro, antes do início das obras da barragem (1974), para alertar sobre o que sucederia com as 72 mil pessoas atingidas, 2/3 camponeses ribeirinhos e catingueiros desprotegidos, e oferecer assessoria à diocese no que o pessoal do CEAS via como desafio pastoral. Em vão. A barragem, imposta pela Ditadura, a produzir energia para o chamado desenvolvimento do Nordeste, foi o desastre anunciado. Uma resposta pastoral à altura só veio depois, a partir de 1975, com a chegada do novo bispo, d. José Rodrigues de Souza e a CPT, cuja criação na diocese ele

\footnotetext{
* Versão modificada da "Carta a Cláudio Perani, que não se queria póstuma", publicada pela ADITAL.

1 "Carlismo" na Bahia designa o esquema de poder e a forma de liderar do governador e senador Antônio Carlos Magalhães (1927-2007), que combinava tecnocracia com mandonismo.
} 
liderou, meses depois da sua fundação no Regional Nordeste III (Bahia e Sergipe) da CNBB (Conferência Nacional dos Bispos do Brasil), em 1976.

Contamos por várias vezes com a assessoria direta de Perani, na diocese e na CPT Regional, e aí éramos iluminados pelo brilho sutil de sua inteligência, a agudeza de sua sensibilidade, a fidelidade do seu compromisso evangélico com os mais pobres, a força tanto maior quanto mais simples - de suas ideias pastorais e valores de evangélica libertação. Devo sobretudo a ele o convencimento de que nosso papel como agentes de pastoral se limitava e se realizava plenamente no simples serviço ao protagonismo dos pobres na luta pela libertação, que não seria se não fosse assim, por eles mesmos, com a força de Deus - a Causa do Reino, nossa Causa. Esta sua marca perdura até hoje na CPT Bahia, tantos anos e tantos agentes depois.

Numa ocasião, nosso entusiasmo pelas oposições sindicais, pela construção da CUT e do PT, teve que se deparar com o realismo da tranquila ponderação de Perani sobre os limites intrínsecos e históricos destes instrumentos de ação. Não foi uma "ducha fria" - ele não era disso -, mas um alerta que calou fundo. Premonitório? Nada disso, só sabedoria mesmo!

É que para Perani o critério da fé e da ação - unidade indissolúvel - sempre foi o pobre, preferido de lahweh e de Jesus, e seu projeto histórico e escatológico. O de Perani não era um Deus etéreo, autoridade máxima distante, mas uma realidade amorosa bem concreta, vivido numa relação experiencial de serviço, cotidiana, contextualizada. Pura fé. Por isso, talvez estivesse achando mal colocado, revisionista e muito afeito ao espírito (ou falta de) do tempo atual, o debate sobre qual a centralidade da Teologia da Libertação, se no pobre ou no Cristo... Questão que até poderia ter sentido se fazer, depois de todo o caminhar desta teologia e sua pastoral correspondente, não fosse o clima reacionário e autoreferente que marcou o período de João Paulo II e Bento XVI à frente da Igreja Católica, cujos efeitos ainda sofremos e dão trabalho ao Papa Francisco.

Numa carta de Manaus de 18.04.1996, sobre as crises da CPT, Perani me dizia: "(...) fundamental o protagonismo dos lavradores. É claro, a palavra serviço não deve ser abusada. No fundo trata-se de uma questão de poder: dos lavradores ou nosso. A tentação do poder nosso é sempre muito grande e pode encontrar mil justificativas, entre outras o pedido dos próprios lavradores. Renunciando ao próprio poder, entramos numa situação de aparente insegurança e indefinição. É aqui que deveria entrar a visão de fé ou a espiritualidade". 
Em comentário a um texto que, em abril de 1997, Ihe mandei, de reflexão da CPT Nacional sobre "relações com o Estado", Perani, veemente, questionou uma citação de Habermas sobre o "nenhum potencial de ruptura" das "subclasses", que seria a "população excedente" resultante da globalização dos mercados financeiros e da própria produção cada vez mais sob controle tecnológico: "Como os excluídos não têm nenhum potencial de ruptura? Só sua existência é uma preocupação grande para o modelo neoliberal. Veja a violência, a política de fertilidade, as migrações...". As medidas repressivas tomadas pelo ultraliberalismo, como a multiplicação dos muros de todos os tipos, estão aí para dar-lhe razão. A ruptura é que ainda não aconteceu...

Sobre as tais relações com o Estado, dizia: "Como é possível, na atual distribuição de forças, o Estado representante dos interesses do capital, pensar em 'parceria cidadã', onde cada um ganhe como igual [conceito de Augusto de Franco]?" A pergunta, atualíssima, azeda o gosto destas vultuosas relações, que submetem, senão praticamente paralisam movimentos sociais, pelos caminhos tortuosos do acesso e exercício limitados do poder do Estado, no legislativo e no executivo, esvaziando ou enviesando as ruas...

Um artiguinho daqueles despretenciosos e fundamentais de Perani nos Cadernos do CEAS - "Sobre as eficácias" (n.150, 1994) - ensinava que à eficácia política e à eficácia econômica, justas e necessárias, se sobrepõe para nós, a "eficácia da presença" gratuita no meio dos pobres e aberta aos seus sinais. Até hoje usamos o texto nos encontros de formação de agentes da CPT e como referência nos cursos com lideranças de movimentos sociais, por vezes ferrenha e estruturalisticamente marxista-leninistas. Sua reflexão é uma primorosa e potente atualização metodológica, social e política do episódio de Pedro e João diante do paralítico esmoler "carregado" diariamente à porta do templo: "ouro e prata eu não tenho, mas o que eu tenho te dou: levanta e anda" (Atos dos Apóstolos 3,6). E o homem pôs se a evangelizar.

Perani era de uma coerência permanente. Uma vez, a nossa "CPZ - Comissão Pastoral da Zombaria", invenção humorística de agentes da diocese de Juazeiro para atender à necessidade de descontrair e rir de si mesmos, ofereceu-lhe uma camisa com o emblema da "gloriosa" comissão - uma foto dos "anjinhos risonhos", parte de um alto relevo da Catedral de Colônia (Alemanha). Expectativa sobre o que faria o "grande" assessor... Ele não teve dúvida, tirou a própria camisa frente a todos e todas, expôs a brancura da pele e vestiu a camisa da "CPZ", aderindo à proposta de "lutar, sim, mas com humor". 
Eu o ouvi dizer que gostava do carnaval, que chegava a ir "atrás do trio elétrico"... E lamentar que fossem poucos dias (em Salvador dura quase uma semana!), pois "se fossem mais, o povo faria aí a revolução!". Só um olhar tão perspicaz e atento veria tão profundamente...

Na verdade, acho que Perani via com o coração o que sua inteligência disciplinada pelo estudo e pela prática Ihe descobria. Quer dizer, via com amor, porque, sobretudo, amava, ao povo que o Evangelho lhe mostrou sofrido, às margens de estradas e caminhos, como os trabalhadores, posseiros e burareiros (pequenos produtores) do cacau, onde por quase 20 anos, duas vezes por mês, ia nos fins de semana, apenas ser/fazer "presença eficaz". Foi dele que ouvi por primeiro que o Evangelho da CPT era o do Bom Samaritano, que, fora da estirpe dos "eleitos", foi quem deu apoio incondicional ao pobre assaltado à beira da estrada de Jerusalém a Jericó, ignorado por sacerdotes e levitas... (Lucas 10, 25-37).

Vindo de lá da região do cacau, uma vez, em assembleia da CPT Bahia/Sergipe, nos inquiriu: "Vocês só têm olhos para os trabalhadores clássicos, não veem os desempregados, os biscateiros, os que vivem de bico, porque não há outra alternativa, de terra ou trabalho? É o que mais se vê hoje, nas beiras das estradas". E aquilo muito nos incomodou... Pouco depois, iria influenciar decisivamente a opção da CPT de Juazeiro em priorizar o trabalho com os assalariados da irrigação, que resultou na criação do SINTAGRO, primeiro sindicato regional (intermunicipal) de assalariados rurais "das empresas agrícolas, agropecuárias e agroindustriais". Foi, de novo, uma equipe do CEAS quem fez a pesquisa que levantou os dados fundamentais para iniciar o trabalho.

A criação da CPT deve muito a Perani, sobretudo o caráter "pastoral popular" da comissão que nascia apoiada pela CNBB. O CEAS, com ele e o Pe. Manuel Andrès, teve papel decisivo não só nas andanças e contatos país afora, que resultaram no subsídio e na articulação de agentes que deu na CPT. No Encontro de Goiânia, entre 19 e 21 de junho de 1975, que originou a CPT, talvez tenham sido as falas e os embates que ele mais alguns companheiros travaram nos corredores - mais do que as escutas de arapongas do SNI e o sumiço de papéis -, os responsáveis pela definição da CPT como "pastoral de serviço", "do conflito" e "nas fronteiras" - era como ele dizia. Tal a diferença de pensamento a respeito da linha estratégica e diante da tendência popular majoritária já bem articulada, os dirigentes da Comissão de Justiça e Paz, também convocados pela CNBB para assessorar o encontro, dele se retiraram. Não fosse Perani, em lúcida e oportuna parceria com outros companheiros 
- expressão de uma ampla e múltipla e mapeada experiência vivida na base -, a nascente "Comissão de Terras" não seria "pastoral", mas uma mera "comissão de notáveis" que interporia, em gabinetes de generais, o prestígio e o peso da Igreja Católica, em favor dos desvalidos da terra avidamente cobiçada pelo capital avançando por sobre índios, posseiros e peões da Amazônia e do Brasil.

Em dois artigos sobre o encontro que criou a CPT, relatórios críticos sobre ele, sabemos como e o que significou aquele momento histórico, na perspectiva da Igreja institucional $^{2}$ e dos trabalhadores rurais ${ }^{3}$. Este último baseava-se no dossiê que o CEAS preparou como subsídio para o encontro. São textos preciosos, singulares, que utilizamos em momentos de formação de agentes, sobre a história e o caráter pastoral da CPT.

Essa história da criação da CPT ouvi do próprio Perani num memorável quase um dia inteiro, por volta de 1996, em Porto Velho - RO, onde ele estava em compromisso como superior dos jesuítas na Amazônia e eu em acompanhamento à CPT Rondônia. Ainda hoje me cobram, mais depois de sua morte, por não ter gravado aquela conversa sobre as origens da CPT... No fundo não me arrependo, não cabia ali um gravador intruso. Era amizade e gratuidade demais para ter preocupação com registro e posteridade. Além das informações preciosas, ficou a memória afetiva e o querer seguir sendo discípulo dele, mesmo sabendo que essa coisa de "mestre" Ihe incomodaria. Porque, no fundo, Perani "só" quis mesmo ser e foi completamente - companheiro de caminhada, Companheiro de Jesus.

Mais cedo do que esperávamos o câncer o levou. Já tinha mesmo cumprido, exemplarmente, a Missão, não merecia maiores sofrimentos ao desterrar-se para o Infinito e Absoluto, que perseguira toda a vida. "Lavado no sangue do Cordeiro, passada a grande tribulação (Apocalipse 7,14)", ele lá sabe. E sabemos nós, aqui, corações ardendo, no caminho iluminado pelo vivo testemunho (martirýa) que nos deixou, ensinou (e aprendeu) conosco.

No dia da notícia de sua passagem, encerrado seu caminho, tinha lido em artigo de João de Barros ("O Araguaia já está morrendo"), na revista Caros Amigos (agosto 2008), Pedro Casaldáliga dizendo "A vida não vale nada. O que vale são as causas para as quais vivemos".

\footnotetext{
2 PERANI, Cláudio. Bispos da Amazônia: a conversão ao posseiro - reflexões teológico-pastorais sobre o encontro das Igrejas da Amazônia Legal em Goiânia. Cadernos do CEAS. Salvador, n. 39, p. 23-31, set./out. 1975 .

3 PERANI, Cláudio. Terra e posseiros na Amazônia legal. Cadernos do CEAS. Salvador, n. 39, p.32-49, set./out. 1975 .
} 
Cai-Ihe bem, pacifica a lembrança e reflete a luz de Perani para seguir em frente meu próprio Caminho.

Ruben Siqueira**

${ }^{* *}$ Agente da CPT (Comissão Pastoral da Terra), na Bahia e na Coordenação Nacional Executiva atual, graduado em Filosofia e Pedagogia e Mestre em Ciências Sociais. 